\title{
Institutional Stakeholder Perceptions on Mobile Number Portability Implementations in Georgia and Belarus
}

\author{
Armen Ghalumyan ${ }^{1 *}$ \\ ${ }^{1}$ Telecom Ecole de Management, France \\ *Corresponding author: Armen Ghalumyan: armghalumyan@yahoo.com
}

\section{OPEN ACCESS}

Citation: Ghalumyan A. (2018) Institutional Stakeholder Perceptions on Mobile Number Portability Implementations in Georgia and Belarus. Open Science Journal 3(4).

Received: $18^{\text {th }}$ May 2018

Accepted: $11^{\text {th }}$ August 2018

Published: $4^{\text {th }}$ October 2018

Copyright:@ 2018 This is an open access article under the terms of the Creative Commons

Attribution License, which permits unrestricted use, distribution, and reproduction in any medium, provided the original author and source are credited.

Funding: The author(s) received no specific funding for this work

Competing Interests: The author have declared that no competing interests exists.

\begin{abstract}
:
Mobile number portability (MNP) is considered an important condition for ensuring full competition in the telecommunications sector, enabling mobile subscribers to change their service providers any time without altering their phone numbers. In global existence already since 1997, within the post-Soviet space it was first introduced only in 2011 and 2012, in Georgia and Belarus respectively. The given article summarises views and perceptions on MNP implementations of relevant institutional stakeholders from those two countries, i.e., mobile operators and national regulatory/ policy-making authorities in charge of the telecommunications field. It was part of a larger research project that studied also the perspective of final consumers (mobile users), which is outside the scope of the present publication.
\end{abstract}

Keywords: Mobile number portability, Georgia, Belarus, Telecommunications, National regulatory authorities, Policy-making bodies, Mobile operators.

\section{Introduction}

Number portability that allows the end user to switch between service providers without changing their phone numbers is one of the fundamental prerequisites for full competition in telecommunications markets, on both mobile and fixed networks. After it was first introduced in 1997, mobile number portability (MNP) has since then been implemented in many countries across the 
globe. Moreover, the European Union has considered it as a vitally important feature, mandating all member states to launch number portability solutions in 2003.

The European law treats number portability as a human right under the EU Universal Service Directive (Directive 2002/22/EC). The current scope of number portability is defined in Directive 2009/136/EC of the European Parliament and of the Council of 25 November 2009, amending Directive 2002/22/EC. According to Article 30 of the Universal Service Directive [1], "Member States shall ensure that all subscribers of publicly available telephone services, including mobile services, who so request can retain their number(s) independently of the undertaking providing the service..."

Further stipulated in Directive 2009/136/EC [2], there are several important conditions to be ensured for the successful implementation of number portability, such as the following:

- Pricing related to the provision of number portability shall be cost oriented, and direct costs to subscribers, if any, shall not act as a disincentive for the use of this service.

- National regulatory authorities (NRAs) shall not impose retail tariffs for the porting of numbers in a way that would distort market competition.

- Porting of numbers shall be implemented within the shortest possible time. In any case, subscribers shall have their ported numbers activated within one working day from the order.

- Loss of service during the porting process shall not exceed one working day.

- Subscribers shall not be switched to another provider against their will.

- Appropriate sanctions on undertakings shall be put in place, including an obligation to compensate subscribers in the case of delay in porting or abuse of porting by them or on their behalf.

- Contracts concluded between consumers and undertakings providing telecommunications services shall not require an initial commitment period exceeding 24 months. Customers shall also be offered the possibility to subscribe to a contract with a maximum duration of 12 months.

As the deployment of an MNP facility carries significant upfront investment and follow-up maintenance cost, it was initially pioneered by mainly developed countries. Contrary to the EU and other parts of the developed world, developing nations including those from the former Soviet Union have been lagging behind with their MNP adoption. According to the GSMA Intelligence research [3], only $25 \%$ of developing markets have implemented MNP. Specifically, Georgia and Belarus were the first states in the post-Soviet region to launch MNP in 2011 and 2012 respectively.

Like with any other service, the demand for MNP is directly correlated with its high usage rates. Policy makers around the world heavily rely on porting statistics as a measure of success of the MNP implementations. The annual data on ported numbers are defined as an indicator by International Telecommunication Union (ITU) and are regularly collected for the latter's 
World Telecommunication/ ICT Indicators database [4]. It is regarded as a noteworthy benchmark also by the European Commission, which includes number portability statistics in its yearly Digital Progress Report, as a dedicated section of telecom country reports for each of the EU member states [5].

In his work on the MNP lessons from international experience, Rohan Samarajiva [6] acknowledges that "in the short term low porting rates may mean failure" and further suggests a formula for the MNP success: "High porting rates $=$ cost-recovery $=$ increase churn/ improve competition $=$ MNP success." At the same time, however, as experience of certain countries shows, high demand for MNP might not necessarily equate to the attained improvements like increased customer satisfaction. Furthermore, although most of the available literature associate the success of MNP with high porting rates, some papers argue that the service implementation could still be successful under low rates of number portings.

For instance, Tahani Iqbal [7] claims that this is likely to be the case if MNP leads to improved market competition resulting in lower tariffs, better services and hence satisfied customers. Therefore, she concludes that "the argument for high porting rates being the sole indicator for the success of the MNP service is erroneous." The same is confirmed by Larkotey et al. [8] in their case study of MNP successes and failures in a number of developing countries from the West African sub-region.

When it comes to porting statistics for Georgia and Belarus, the former had reached more than 107 thousand number portings in just one year since the service launch. In contrast, the number of ported mobile subscribers in Belarus in the first 4 months after the MNP introduction amounted to some 2,000 people, constituting only $0.019 \%$ of the country's total subscriber base of 10.7 million.

The question may arise here: do these figures indicate that the MNP implementation was successful in Georgia but rather unsuccessful in Belarus? Absolutely not, as the number of portings alone is an insufficiently adequate criterion to assess the impact of MNP. It is merely a simple reference for policy makers to quantify the demand for MNP, which should be accounted for throughout the entire period since the service introduction and not at a single point in time, together with some other quantitative as well as qualitative aspects.

A more holistic insight into the effects of MNP would imply the application of a multi-stakeholder impact analysis, taking account of all relevant stakeholder groups such as final consumers, regulatory and/or policy-making bodies, and mobile operators. This was the approach followed in the study of MNP implementations in Georgia and Belarus, carried out during 2014-2017 within the framework of the author's doctoral program. With several years already in place in those countries, the MNP service has accumulated certain track record to research for.

The given article summarises views and perceptions of the key institutional parties concerned, with an attempt to provide a broader picture on whether MNP has resulted in any essential effect on the telecommunications markets of Georgia and Belarus. 


\section{Historic overview of international MNP experience}

Historically, users of telecommunications services had to abandon their phone numbers when changing providers/ networks. This situation prevented the development of effective competition, particularly in the fast-growing mobile telecommunications sector, as consumers were reluctant to switch between the incumbent operator and latest market entrants. However, this state of affairs has notably changed with the widespread implementation of number portability (especially mobile number portability) across the European Union and many other countries all over the globe, having the enhancement of competition as one of its major aims.

Singapore became the first country in the world to implement MNP in 1997. The first European countries to launch MNP were the UK and the Netherlands, both in 1999. Other EU member states followed the trend, before the MNP implementation was mandated across the entire EU space in 2003. As a result, the subscriber churn levels in some European incumbents increased dramatically, with the third or fourth operators by subscriptions gaining significant market shares.

However, the picture with the MNP usage has been considerably different across countries. If the number of portings is taken as a simple indicator for the success of MNP, the revealed statistics are not homogeneous in terms of the average monthly portings and the percentage of mobile subscribers who ported their numbers. Buehler at al. [9] collected data on ported numbers in several European countries for the period from the inception of the MNP service in a given country till August 2004 (Table). Within country-specific timeframes, Finland and Denmark achieved the highest MNP uptake as a percentage of all mobile subscribers.

Table: Number of mobile portings in European countries

\begin{tabular}{lllll}
\hline Country & Period & Ported numbers & $\begin{array}{l}\text { Avg. ported } \\
\text { numbers } \\
\text { (monthly) }\end{array}$ & $\begin{array}{l}\text { Percentage of all } \\
\text { subscribers }\end{array}$ \\
\hline UK & & $44,659.75$ & 5.6 \\
Italy & $1 / 1999-8 / 2004$ & $3,036,863$ & $89,285.71$ & 4.5 \\
Spain & $5 / 2002-8 / 2004$ & $2,500,000$ & $59,595.95$ & $\mathbf{2 0 . 8}$ \\
Finland & $12 / 2002-8 / 2004$ & $2,091,515$ & $\mathbf{7 6 , 4 2 9 . 0 7}$ & 6.9 \\
Netherlands & $\mathbf{7 / 2 0 0 3 - 8 / 2 0 0 4}$ & $\mathbf{9 9 3 , 5 7 8}$ & $17,459.30$ & $\mathbf{1 7 . 8}$ \\
Denmark & $4 / 1999-8 / 2004$ & 925,343 & $\mathbf{3 5 , 3 0 7 . 6 9}$ & 6.2 \\
Belgium & $\mathbf{7 / 2 0 0 1 - 8 / 2 0 0 4}$ & $\mathbf{9 1 8 , 0 0 0}$ & $21,756.86$ & 5.6 \\
Sweden & $10 / 2002-8 / 2004$ & 500,408 & $13,526.00$ & 0.6 \\
Germany & $9 / 2001-8 / 2004$ & 486,936 & $15,863.63$ & 4.1 \\
Ireland & $11 / 2002-8 / 2004$ & 349,000 & $10,954.92$ & $\mathrm{n} / \mathrm{a}$ \\
Lithuania & $7 / 2003-8 / 2004$ & 142,414 & $16,250.00$ & 0.2 \\
France & $1 / 2004-8 / 2004$ & 130,000 & $7,142.85$ & 0.4 \\
Portugal & $7 / 2003-8 / 2004$ & 100,000 & $1,094.75$ & $\mathrm{n} / \mathrm{a}$ \\
Hungary & $1 / 2002-8 / 2004$ & 35,032 & $3,468.75$ & $<0.1$ \\
Cyprus & $5 / 2004-8 / 2004$ & 13,875 & 65.33 & \\
\hline
\end{tabular}


The situation did not seem to change as of October 2008. Cho at al. [10] in their study of the impact of MNP on price, competition and consumer welfare still show the large variation in the percentage of mobile customers who ported their numbers in the examined European countries. Values on Figure below represent the cumulative proportion of mobile portings out of total subscribers within the period since the MNP introduction till October 2008. As before, Finland and Denmark were among the leaders with their mobile portings, whereas Portugal and Germany were at the bottom of the country list with as low as $1.4 \%$ of MNP users out of total mobile customers.

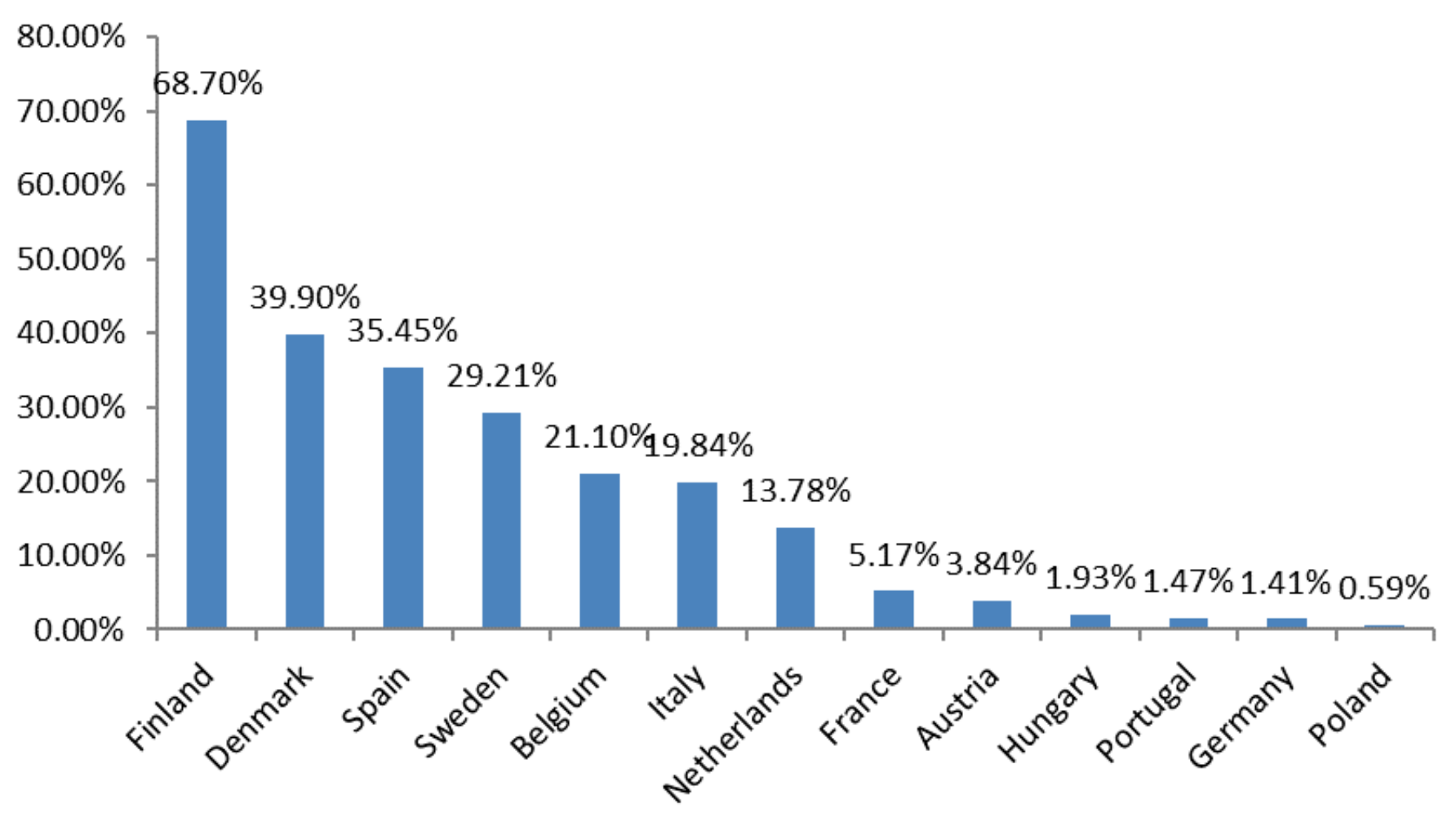

Figure: Percentage of mobile portings over total subscribers in European countries

Some further statistics on a number of select countries are provided by Levin [11] to reflect on heterogeneity of the MNP use across countries. It proves the fact that the number of portings is not correlated with the length of time the MNP service has been in place in a particular country. For instance:

- In Finland, $16 \%$ of mobile customers ported their numbers within 8 months from the MNP service launch.

- In Portugal, a tiny percentage $(0.28 \%)$ of total customers used the MNP option within 27 months from the service launch.

- In Hong Kong, a total of $85 \%$ of mobile customers used the MNP option within 60 months from the service launch.

- In the UK, only $5 \%$ of mobile customers ported their numbers within 63 months from the MNP service launch. 
As another example, Germany introduced MNP in November 2002 and recorded one of the lowest usage rates among European countries; only $0.43 \%$ of mobile customers ported their numbers after 15 months from the service launch. This was due to incredibly lengthy porting periods (up to 31 working days), quite high porting charges and poor marketing of the service by mobile operators.

The above statistics indicate that the initial MNP experience in the EU was not entirely successful with ensuring sufficient incentives for mobile customers to use the facility, specifically in terms of reasonable porting charges and acceptable porting speeds. In a move to make the MNP rules more user-friendly and to strengthen the MNP effect in future, in 2009 the European Union updated its corresponding policy set forth in the Universal Service Directive of 2002 (Directive 2002/22/EC). Therefore, the currently applicable number portability terms and conditions in Europe are specified in Article 30 (Facilitating Change of Providers) of Directive 2009/13/EC that amended the 2002 Directive.

Article $30(2)$ of the amended text reads that "national regulatory authorities shall ensure that pricing between operators and/or service providers related to the provision of number portability is cost-oriented, and that direct charges to subscribers, if any, do not act as a disincentive for subscribers against changing service provider." Furthermore, Article 30(4) stipulates that "porting of numbers and their subsequent activation shall be carried out within the shortest possible time. In any case, subscribers who have concluded an agreement to port a number to a new undertaking shall have that number activated within one working day." All member states were mandated to transpose these changes into their national legislations before 2011.

As a consequence, the enactment of those new rules had positively affected the European statistics for mobile portings. In 2010, 2011 and the first quarter of 2012 France, Italy and Spain were already among the EU member states with largest volumes of ported numbers. Those countries had active third- or fourthplaced mobile operators that were well positioned to take advantage of the MNP availability, to effectively compete with incumbents by offering cheaper deals and better service quality.

Beyond the EU, the developing world has yet been slow with its MNP adoption. It was already implemented in many of the largest states such as Brazil, India, Mexico, Turkey and South Africa, whereas some other countries are known to plan its introduction in the future. As an example, Turkey has experienced a great impact from MNP, where it was implemented in November 2008. Within 5 months after the service launch, some two million mobile numbers were already ported. At the initial stage, the third operator by subscriptions reaped most benefits but afterwards the second-placed operator took the lead as a result of its aggressive promotional campaigns.

As opposed to MNP adopters, quite a lot of developing countries either have declined the option or are still indecisive in this regard. It is already apparent that many regulators in Asia and Africa are not enthusiastic about MNP. For instance, the Maldives and Uganda have made a decision not to implement MNP as it was estimated to be too expensive for these developing nations.

As it is reflected by the above porting statistics, the worldwide MNP track record has seen varying implementation outcomes, ranging from largely successful to nearly unnoted as well as depending on a great deal of particular country and market specifics. The case of both Georgia and Belarus fits this overall pattern, 
as evidenced from the relatively large number of mobile portings in the former country and a significantly lower proportion of MNP users as a percentage of total subscribers in the latter one.

However, these numeric data are only an easily quantifiable side of MNP. Behind those numbers, there are also supplementing qualitative aspects that can be revealed from direct feedback by major relevant stakeholders, i.e., final consumers, NRAs/ policy-making bodies and mobile operators. When taken together, they can lead to a more meaningful review of MNP effects.

As it relates to the decision on whether or not to introduce an MNP system, it ultimately depends on the analysis of underlying costs and benefits. The implementation costs are typically high and so the expected benefits should outweigh them. The former category is relatively easy to present and estimate, whereas the latter one is much more difficult to quantify as it contains unpredictable factors and intangible features that are hard to attribute a monetary value to. The next section discusses both of them from the perspective of national regulators/ policy makers and mobile operators.

\section{Costs and benefits of MNP}

The MNP costs can be distinguished between direct and indirect. In turn, direct costs of implementing and maintaining an MNP system are further divided into the following:

- $\quad$ setup costs (upgrade of the network infrastructure to support the MNP solution);

- maintenance costs of the MNP system; and

- actual porting costs (usage of network resources to route the calls to ported numbers, etc.).

These costs are heavily dependent on the choice of a technical solution to introduce MNP. The setup cost is a one-off expense to design and implement the system, and this sizable investment is usually a significant hindering factor for the MNP deployment in any country. The setup cost consists of many different components such as for installing a centralised number portability database that contains the complete porting information, developing the necessary software, defining operational procedures to port a number, etc.

In addition to that, each mobile operator has to ensure that their operational servers are capable of interacting with the centralised database through a defined interface. These are all fixed costs, with no dependence on the number of portings or the volume of routed traffic. Furthermore, future hardware/ software upgrades and regular maintenance once the MNP system is in place will add to the initial investment cost.

Besides, the actual porting process involves variable costs related to advising consumers, activating the numbers ported, providing the routing information, ensuring communication between operators of the donor and recipient networks, and so forth. These are mostly personnel costs based on adopted technical and administrative procedures. 
Apart from the above, the introduction of MNP brings about indirect costs associated with the likely loss of tariff transparency, i.e., difficulty on the part of customers to distinguish between different mobile networks by referring to a number prefix. Therefore, if charges for making a call vary between mobile operators, subscribers will potentially not have the comprehensive information about applicable calling rates.

To solve this problem, mobile operators come up with a range of technical solutions. For example, in some countries customers have the option to learn about their mobile number's network assignment through toll-free enquiry numbers or SMS services. As an alternative means, subscribers placing an off-net call may receive an alert by an acoustic signal or a verbal announcement before the call commences.

To be able to recover their MNP-related costs, mobile operators charge a price for providing the service. The European Union in its Universal Service Directive requires from all member states that porting prices should be based on costs, and the EU countries have enforced regulations prohibiting to set porting charges above costs. It is another question who should bear the cost of porting a number; most frequently, MNP is a free service for mobile phone users, with the porting price charged to the recipient network by the donor operator.

In total, the cost of implementing MNP is estimated to be quite high. It therefore demands thoughtful formulation of the MNP policy and careful consideration of all benefits to understand if those exceed the above described operator costs, to eventually provide the main rationale for introducing MNP.

In reality, many established operators view number portability as a financial and implementation burden, ending up in increased competition, lower prices and hence moderate profit margins. For that reason, the service introduction is normally opposed by incumbent operators but is rather actively advocated for by new market entrants. The latter rely on it as a means for gaining a critical subscriber and revenue base to sustain longer-term operations. Number portability is thus expected to take market concentration away from incumbents and to re-distribute market shares more evenly among all existing players.

With the possibility to easily change carriers, subscriber churn turns into a significant challenge for market entities. As a consequence, they may engage in tough price competition as a tactical move to retain existing customers and attract new ones but cannot afford keeping up with it endlessly under the pressure of maintaining reasonable profit margins. Therefore, operators become more focused on creating additional value for subscribers rather than continuing price wars with rivals. As such, they tend to initiate loyalty programs, improve customer service, extend network coverage and roll out new offers.

In countries where operators took a proactive stance in preparing for number portability, they were able to increase net subscriber additions in the face of more intense competition. This was achieved through a combination of customer service and network improvements, targeted advertising and, to a lesser degree, more competitive rate plans.

As a policy-making tool aimed at promoting active market competition and ensuring enhanced subscriber mobility, MNP has become one of the most widely applied regulatory policies in mobile communications markets worldwide. Hence, the MNP deployment project is often triggered by national regulatory or policymaking bodies in charge of the telecommunications sector. 
In any case, even if the MNP initiative is pushed forward by NRAs/ policy makers, the bulk of actual implementation costs still remains with mobile operators. There might be some costs on the part of governmental authorities, such as connected with organising regular coordination meetings to oversee and monitor the process. The government may also incur costs for providing technical advice to mobile operators in the form of engaging external, often international experts. However, the latter is normally done by commercial undertakings themselves.

In terms of expectations, NRAs/ policy-making bodies follow their own agenda from the effective implementation of number portability, which includes, among others, the following important benefits/ outcomes:

- Competition in the telecommunications market is enhanced, resulting in wider consumer choice, lower tariffs and better quality of service.

- Level playing field is created for latest market entrants to successfully compete with more established players/ incumbent operators.

- Innovation and introduction of new services is stimulated to attract investment in the telecommunications sector and to promote its further development.

- Taking into consideration the number portability's impact on the national numbering plan, numbering resources are utilised more efficiently, thus leaving free capacity and flexibility in structuring the numbering plan and accommodating new subscribers and services.

Narrated later in the text, the given paper summarises expectations from MNP of the relevant governmental stakeholders and of functioning mobile operators in Georgia and Belarus. It is combined with their views and perceptions regarding the effects of MNP implementations, in an attempt to address research questions put forward in the following section.

\section{Research novelty and applied methodology}

There has been no comprehensive, ex post research previously conducted on MNP effects in Georgia and Belarus, at least among publicly available sources. The choice of these countries was conditioned by the fact that they were the first from the former Soviet Union republics to introduce MNP (Latvia, Lithuania and Estonia were actually earlier with their MNP implementations, but they joined the European Union and so number portability became a legal requirement for them).

On the methodology side, formerly carried out MNP research either looks into mobile operator-level panel data or surveys at an end-user level, or rarely utilises a combination of both methods. The larger research project within the framework of the author's doctoral studies appears to be unique in a sense that it gathers and analyses views and considerations of all key stakeholder groups, namely end users, mobile operators and national regulatory and/or policy-making authorities for the telecommunications field (the analysis of consumer survey data is outside the scope of this publication). This multi-stakeholder approach was expected to provide a broader picture of perceptions on MNP effects in the studied countries. 
From the academic point of view, research fellows may find it relevant to apply a similar multi-stakeholder data gathering and analysis framework in their studies of MNP effects in other countries. In fact, it might not necessarily be telecoms-related research but could be applicable to any field alike, e.g., utility sectors like energy, water supply, transport, etc. Besides, this study may serve as a theoretical background and reference point for further research on the same topic and countries, thus contributing to the subsequent academic discussion and development of theory.

In terms of practical application, it is believed that the present research findings might be useful for other nations from the post-Soviet space and beyond that are still in the process of taking a decision regarding the necessity of the MNP service. Adopting best practices and learning from mistakes of those countries that have already pioneered MNP would possibly make the others' implementation path easier.

The performed research was aimed to find out:

1. What the perceptions of key stakeholder groups (i.e., final consumers, mobile operators and telecoms sector regulators/ policy makers) were about the MNP service effectiveness and whether it was successful in meeting its intended objectives.

2. Whether the revealed stakeholder perceptions were supported by certain quantitative indicators on MNP effects such as the reduction in retail mobile prices, change in operator market shares and some others, which were pointed out in the available literature on previous MNP research in other countries.

Thus, the central research question was formulated as to whether MNP implementations have had any remarkable effect on the telecommunications markets of Georgia and Belarus. It was then narrowed down to specific subsets of questions for each of the targeted stakeholder groups. As the given paper is only focused on the summary of institutional stakeholder interviews, the following respective questionnaires are provided in appendices:

- Appendix A - Interview questionnaire for national regulatory authorities/ policy-making bodies (13 questions in total); and

- Appendix B - Interview questionnaire for mobile operators (19 questions in total).

The data gathering tools consisted mainly of open-ended questions to reveal the respondents' opinions around different aspects related to the MNP implementation. It should be noted that some of the questions addressed to the two stakeholder groups were common, as they were expected to closely cooperate during the MNP launch project but could have potentially opposing views over the same issue. The interview questionnaires were first drafted in English and then translated into Russian, as this language is quite widely used in both of the studied countries, especially in Belarus.

The piece of research presented herein involved collection of primary data by means of addressing the stakeholder-specific questionnaires to their intended audiences. After the data gathering process was over, the summary of interviewee feedback was then compiled, bearing in mind best international MNP practice and specifics. 
To complement qualitative findings with a quantitative review of the MNP effect on mobile operators' performance, a desktop study of available data on certain operational and financial indicators was conducted afterwards. Although any change in performance over time could not be attributed solely to the MNP availability, it might provide potential signs of whether MNP was indeed beneficial for individual market players and the telecommunications sector as a whole. This analysis, however, is not included in the present publication.

\section{Market and regulatory context in the studied countries}

By the end of the twentieth century, telecommunications sectors in both Georgia and Belarus had been heavily associated with the existence of statebacked monopoly, held by the national incumbent operators in all market segments related to the provision of fixed and mobile telephony services. The state had still maintained $100 \%$ stake in the incumbents' companies and thus had little stimulus for investment in the sector's development. The inevitable process of liberalisation and privatisation started in late 1990s/ early 2000s, gradually leading to more competitive telecommunications markets [12].

As of now, the Georgian state does not retain any ownership in the sector, whereas the government of Belarus continues to fully control the incumbent fixed operator and also possesses varying degrees of interest in some of the mobile players. Moreover, in view of traffic control by the Belarusian state, the national fixed incumbent Beltelecom remains in a monopoly position for call transit, authorised to obligate interconnection between alternative operators (including mobile ones) on its network.

The telecommunications markets in both countries are regulated by respective authorities: the Georgian National Communications Commission (GNCC) and the Ministry of Communications and Informatisation (MCI) of the Republic of Belarus. The way of regulation has yet been different from what is practiced in the European Union, where NRAs deeply analyse on a periodic basis all relevant markets recommended for ex ante regulation, identify operators with significant market power (SMP) and impose regulatory remedies required to ensure effective market competition.

Up until recently, it has taken more of an ex post nature in Georgia and Belarus, whereby the regulators' role is mostly to intervene in disputes between service providers, to deal with consumer complaints and to settle market abuses after they have occurred. However, Georgia is already in the process of approximating its regulatory framework with that of the EU as part of their association agreement.

The regulatory regimes at time of the MNP launch did not seem to impact the service implementation and provision in the two studied countries. All related procedures and rules, such as how donor and recipient operators should interact, what required conditions must be satisfied before proceeding with a porting request, and what the maximim porting duration and charges should be, were prescribed in advance by legally binding instruments. 
As the MNP availability was expected to limit cross-subsidisation between onnet and off-net mobile call prices, the effect from the service in Georgia and Belarus could have possibly been stronger if mobile termination rates (MTRs) and interconnection charges were regulated, which form a distinct element in the cost structure of a mobile voice call price. Nevertheless, those had not been regulated either before or immediately after the MNP introduction.

\section{Data gathering and analysis process}

As it was already mentioned, separate data collection instruments in the form of questionnaires were designed for each of the stakeholder categories (Appendices A and B). Those were aimed at requesting respondents to freely express their thoughts during structured interviews (either face-to-face or via Skype), each to last for approximately an hour.

The data gathering process among institutional stakeholders, i.e., NRAs/ policy-making bodies and mobile operators, took place in the following time periods:

- Georgia: 9-11 June 2015

- Belarus: 24 June - 8 July 2015

For Georgia, all 5 interviews (3 with mobile operators and 2 with the NRA and a policy-making body) were conducted in a face-to-face mode at the interviewees' premises in the capital city of Tbilisi. For Belarus, 2 interviews with one of the mobile operators and the Ministry of Communications and Informatisation (MCI) were held via Skype, whereas another mobile operator responded to the questionnaire in writing and provided its feedback by email. The remaining third mobile operator, Mobile TeleSystems (MTS Belarus), did not respond to several email requests to participate in the survey, in spite of the fact that the MCI asked them to do so and at first the company replied positively to the Ministry's mediation.

The interviews were recorded upon the consent of interviewees, and based on those recordings the below summary of stakeholder responses was prepared.

\section{Summary of stakeholder interviews}

\section{Georgia}

The following institutional stakeholders were interviewed in Georgia (see Appendix $\mathrm{C}$ for names and contact details of individual respondents met with):

1. NRA - Georgian National Communications Commission (GNCC)

2. Policy-making body - Ministry of Economy and Sustainable Development of Georgia

3. MagtiCom (first entrant mobile operator)

4. Geocell (second entrant mobile operator)

5. Mobitel (latest entrant mobile operator) 
The national policy-making body and the regulatory authority indicated several objectives targeted at achieving through the introduction of MNP. Among others, the following were voiced out:

- $\quad$ pursuit of relevant ITU and EC recommendations;

- $\quad$ promotion of effective competition in the mobile telephony segment;

- further development of the telecommunications sector;

- $\quad$ reduction of mobile tariffs;

- $\quad$ increase in mobile service quality;

- $\quad$ promotion of consumer choice; and

- $\quad$ establishment of a supportive legal and regulatory environment for fostering investment in the telecommunications field.

As a result, the decision binding for all operators was taken to introduce the MNP system as of February 2011. It seems that only the latest market entrant Mobitel was supporting the idea, as it was viewed a good chance to enlarge their subscriber base through possible portings. However, all Georgian mobile operators were objecting against the limited timeframe allowed for implementation (less than six months from the adopted decision till the set golive date). When it became clear that the regulator would be strict with maintaining the deadline, the operators started to cooperate towards the common goal of launching the service on 15 February 2011. In fact, the Georgian MNP implementation is regarded as one of the quickest in the overall MNP history.

Neither the regulator nor mobile operators conducted any thorough ex ante assessments / feasibility studies on potential effects of MNP. The reason for that was mentioned to be the severe lack of time before the implementation deadline. Therefore, none of the interview respondents were able to indicate any specific, quantitative market outcomes they were expecting to achieve, e.g., in terms of the targeted number of mobile portings, the percentage change in mobile prices and market shares, etc. As per rough estimations of one of the mobile operators, it was predicted to have around 10-15 thousand net portings in a year.

The governmental stakeholders (the Ministry and the regulator) were of a strong belief that their expectations from the introduction of MNP were largely met. When it comes to mobile operators, their views in this regard were quite neutral. They indicated that the two government tenders for the provision of mobile services, held since the MNP launch, significantly contributed to the movement of subscribers among operators. There was no definite answer that one operator was better off whereas the other one was worse off from MNP. In terms of the ex post assessment of actual results, all mobile carriers submit on a periodic basis certain MNP-related statistics to the GNCC, which are then analysed by the regulator and published on its analytical portal.

All interview respondents pointed out that there was effective cooperation among involved stakeholders throughout the whole implementation process. The regulator held coordination meetings with mobile operators to oversee the progress achieved. In most cases, operators had to rely on an experienced expert advice by hiring external consultancy services from either their company headquarters or other specialised entities. The tight timeline for launching the service forced all parties to put aside their counter-arguments and objections, mobilise available resources, and work together as collaboratively as possible. 
The Georgian MNP facility satisfies nearly all of the characteristics identified in international research for an ideal MNP regime [13]:

- The porting process is fully driven by the recipient network.

- The centralised number portability database is administered by an independent third-party entity.

- $\quad$ Direct call routing is implemented through an All Call Query (ACQ) method, which is an approach to handling calls to ported numbers whereby the originating operator identifies the recipient provider and routes the call directly to the recipient's network.

- Porting of a mobile number takes place in two to three working days (minimum and maximum porting durations) from the receipt of a porting request.

- $\quad$ Porting is free of charge for mobile customers.

Almost all mobile operators were skeptical about the choice of an independent entity model for ownership, administration and management of the number portability database. However, there was also a controversy in opinions if a consortium of mobile operators could have been a better choice or not; some respondents said this could have allowed keeping implementation costs down, whereas others argued that the mobile operators could have hardly cooperated effectively.

The calculation method of each operator's contribution towards the centralised database maintenance was heavily criticised, claiming that at the initial stage the approach was insufficiently transparent and the cost was unreasonably high. The basis for calculation was the fixed rate multiplied by the total number of mobile phone numbers in all numbering ranges in possession of a particular mobile operator, while the mobile carriers believed that the fixed rate should have been applied to the number of mobile portings instead. The cost calculation method had not been altered before 2014 and there was even a court case around this issue. Although the cost seemed to have considerably decreased afterwards, the operators had serious concerns that the high level of profits earned by the number portability company in early stages of the MNP implementation made it possible to fully recover their upfront investment and to quickly breakeven.

In general, strong competition in the Georgian mobile telephony market has driven prices down for both on-net and off-net calls. Therefore, it is not clear if this downward effect can be attributed to the introduction of MNP. In the national regulator's view, the reduction in mobile call charges was partly due to the MNP launch. Quite surprisingly, one of the Georgian mobile operators was even able to offer a zero rate for its off-net calls, to win the bid in a recent government tender for the delivery of mobile telephony services.

All of the interview respondents confirmed that the MNP service existence was sufficiently popularised. The state had its own stake in providing relevant information to the general public. In their turn, the commercial operators held large marketing campaigns to heavily promote the service among Georgian mobile users. This contributed to the increased level of MNP awareness as well as the establishment of a favourable environment for the subscriber mobility, whereby mobile customers were permitted to freely port their numbers during ongoing contracts after the compulsory 30-day period with a given provider. 
All mobile operators stated that they continuously monitor their mobile service quality, including by analysing their subscribers' feedback through regular customer satisfaction surveys. These are carried out on a quarterly or more frequent basis. In addition to keeping an eye on their service quality and taking necessary steps to improve it further, they engage in efforts to expand their network coverage, introduce advanced services, and initiate customer loyalty programs to retain their existing subscribers and attract new ones. This is regarded strategically important for their long-term functioning and development and is done irrespective of whether MNP has been in place or not. As a noteworthy example, the launch of $4 \mathrm{G}$ services in February 2015 was mentioned.

In early years of the worldwide MNP experience, cases of artificially delaying the porting process by mobile carriers were quite common. Regulatory provisions in many countries still require operators to compensate end users for unduly justified porting delays. As porting procedures have been streamlined and fully automated over time, the occurrence rate of such cases becomes much lower. This was also confirmed for Georgia, as none of the respondent mobile operators recalled an occasion when an artificial porting delay was recorded and they were warned/ mandated by the regulator to provide compensation to affected mobile customers.

In terms of an overall impact that the MNP implementation has had on the corporate performance, the Georgian mobile operators were quire skeptical about it. They said it was good at the beginning but then it went neutral. For companies ended up with a positive net portings balance (ported-in minus ported-out numbers), the availability of MNP provided with an additional opportunity to gain new customers. For all others, it was a good stimulus to shake up their existing business models to accommodate requirements of a changing competitive landscape. However, the mobile operators indicated about the trend of decreasing mobile service revenues as one of the main measures of their performance, which could not be attributed as the direct effect of MNP but perhaps a consequence of intensified competition it fostered.

Finally, the interviewed governmental and commercial stakeholders were of a general opinion that the Georgian mobile telephony market had overall benefited from the introduction of MNP. In particular, they mentioned that it brought about various economic and social effects as it related to the increased wellbeing of mobile users as a result of enhanced consumer choice, inter-operator mobility and mobile service quality as well as of reduced call charges. Again, the mobile operators complained about their decreasing revenues, which seemed to be a sector-wide trend not directly associated with MNP.

\section{Belarus}

The following institutional stakeholders in Belarus provided responses to the designed questionnaires (Appendix D contains names and contact details of individual interviewees):

1. Policy-making body - Ministry of Communications and Informatisation of the Republic of Belarus

2. BeST (latest entrant mobile operator)

3. velcom (earlier entrant mobile operator) 
Several regulatory aims were followed by the national policy-making body for the implementation of MNP, particularly to stimulate market competition and increase mobile service quality. In addition, the latest market entrant BeST raised this requirement as a pre-condition for making investments foreseen by its licence; as such, it was the only supporter of MNP among the Belarusian mobile operators. Other market players were neutral and/or opposing parties, as they believed that the MNP introduction was not driven by the market demand but rather by the state's obligations towards the third player. One of the respondent mobile operators named it as unjustified investment and wasted time, due to knowingly absence of demand for the service.

The ex ante assessments of potential effects from MNP were conducted for the national telecoms administration and the mobile operator BeST. However, these were intended for the internal use only and are not publicly available. The Ministry's expectations were met partially, specifically after the MNP regime had changed to a recipient-driven process (initially within two years from the service launch up to 2014, it had been donor-led). According to forecasts, the latest entrant BeST expected to gain 300,000-700,000 new subscribers within a certain timeframe after the MNP implementation, which did not materialise. In general, the company's executive was of a strong view that the fullest MNP impact could only be possible to achieve in conjunction with the proper regulation of mobile termination rates (MTRs) and interconnection charges, which was not the case.

More established, competing mobile operators did not carry out prior-MNP assessments and did not predict any significant changes in the market as a result of the service introduction; in this sense, their assumptions largely proved to be correct in terms of the lack of demand for the MNP facility.

The Ministry of Communications and Informatisation did its best to organise coordination meetings with all mobile operators during the MNP planning phase. Closer to the targeted go-live date, those were held nearly every week. However, the technical expertise required for implementation was mostly arranged for by the operators themselves. It seemed to be a seamless working process, though the latest entrant claimed that the effectiveness of cooperation was hindered by the two opposing competitors trying to delay the MNP introduction.

The MNP approach and specific attributes have changed in Belarus over time. As it was already mentioned above, in the early stage of the MNP implementation the porting process had to be initiated by the donor operator. Also, mobile customers were charged a fee for porting their numbers. Since 2014, switching subscribers need to apply only to new carriers of their choice and they don't pay anything to have their phone numbers ported. The overall duration from the porting request submission till the number activation by the recipient operator falls within 24 hours, though simultaneous porting of a bulk of mobile numbers may sometimes be lengthy and problematic. As a technical solution to route calls to ported numbers, the system employs direct call routing. In general, the MNP regime in Belarus largely meets certain criteria to be claimed effective; however, it is still considered to be premature.

The centralised database has been administered by the national fixed incumbent, "Beltelecom" Republican Unitary Enterprise. The stakeholders believed it was the right choice, but setting the tariffs for maintenance should not be the prerogative of the database owner and should have been regulated by the 
state. One of the mobile operators was of the view that the fee charged for the use of the centralised database is not transparent and there is a disagreement on every occasion Beltelecom decides to rise it. The level of CAPEX was quite significant for each mobile carrier to establish their own operational databases, and it was suspected that the initial investment would never be recovered. The ongoing OPEX mainly consist of regular usage payments made to the centralised database administrator.

Opinions were divided regarding the impact of MNP on mobile call prices. On one hand, there was a belief that the service availability in no way influenced the tariffs, which were already so low that their further dramatic decline would hardly be possible. On the other hand, a view was expressed that the MNP introduction contributed to better tariffs, specifically for off-net calls. This effect has in its turn led to the increase in off-net traffic volume. Nevertheless, the operators complained that it was almost unrealistic to maintain adequate profit margins under the conditions of high MTRs.

The latest entrant BeST engaged in heavy marketing campaigns to promote the MNP service as widely as possible; two separate campaigns were still active at the time of the interview. Thanks to those massive popularisation efforts, MNP was sometimes perceived on the part of mobile users as an innovation by BeST, at least on a psychological and emotional side. The company considered that to be rewarding experience, even though it did not deliver much fruit in terms of an increasing number of ported-in subscribers. In contrast, the two competitors were far less inclined to extensively market MNP; one of the interviewees stated that they never viewed the service as sufficiently deserving to expend on its marketing.

Logically, mobile operators in Belarus are concerned about their customers' feedback regarding the quality of service they provide, which is being assessed on a regular basis (quarterly or depending on the market situation at a particular point in time). It is usually measured against a set of defined parameters, e.g., key performance indicators (KPIs) as part of the annual scorecard. Call centers/ reference and information services are set up to handle consumers' questions and complaints.

To increase loyalty of their existing subscribers and prevent possible churn, all the companies take a range of steps to further improve their mobile service quality and expand network coverage. This work is done continuously to maintain a competitive position on the market and is not connected with MNP. One of the respondents named Belarusian people as being quite conservative who hardly change their current habits, but under poor service quality they would definitely look into the possibility of switching to another mobile carrier perceived as providing comparably better service. Therefore, always keeping an eye on the degree of customers' satisfaction is a critical condition for not losing them to a competitor.

The subscriber contracts are normally concluded for an indefinite term. Termination of a contract is the customer's right and even if a specific term is stipulated, porting of a mobile number implies early cancellation bearing certain liabilities envisaged by both the contract itself and the relevant legislation. The allowable porting frequency of a phone number is set in the law at maximum one porting within every 3 months. 
None of the interviewed mobile operators reported that they were ever warned or fined by the respective authorities for delaying the porting process without any reasonable justification. If it does happen though, an end user may file a complaint to the telecoms administration or apply to court. These bodies may then turn to their specific measures against the contravening operator.

Taking into account all of the above realities of the MNP regime in Belarus, the national policy maker for the telecommunications field believed that the introduction of the facility had an overall positive impact for the sector's development and strengthening of competition, despite the fact that it left the industry expectations largely unmet. On the contrary, the interviewed mobile operators took a completely different point of view, stating that MNP was totally insignificant for their companies in particular and the mobile services market in general.

For the most part, the service has been unclaimed by mobile users since its launch, which is evidenced from the low numbers of mobile portings. As a true supporter of the MNP implementation, the latest entrant BeST attributed its failure to high interconnection and termination rates. The company strongly doubted that MNP would have any tangible effect without regulating them. Besides, the change of a service provider comes at a high switching cost, which essentially makes mobile customers unwilling to port.

\section{Discussion and conclusions}

After over 20 years of the global MNP existence, it has largely been considered a success story, benefitting all relevant stakeholder groups such as end users, mobile operators and regulatory or policy-making authorities in charge of the telecommunications sector. It is expected to bring about various socioeconomic effects as a result of enhanced consumer choice and inter-operator mobility.

For commercial players, the MNP availability is an additional means to gain new customers and a good stimulus to shake up their strategic and operational models to adapt to a changing competitive environment. For regulators and policy makers, it is a tool for enhancing market competition and promoting innovation and investment in the sector.

However, the actual uptake of the MNP service is not homogeneous throughout the world and has proven to be different from one country to another, ranging from considerably high to almost negligible. This varying pattern can be attributed to the degrees of market efficiency and other influential factors associated with country specifics.

In the two studied countries, the MNP project was initiated by the national telecoms regulator or policy maker, pursuing a range of specific objectives. In addition to the government authorities, the latest entrant mobile operators were the only supporters of the idea. The governmental stakeholders were of the opinion that their expectations from the MNP introduction were largely or partially achieved, leaving an overall positive impact on the sector's development and strengthening of competition. 
As to mobile operators, their views on the effects of MNP were mostly neutral or skeptical, even those of the latest entrants that were actively lobbying for the service during its pre-launch period and were expected to reap much needed benefits from it. They believed that MNP was mostly insignificant for the performance of their companies in particular and of the mobile services market in general.

The MNP facilities in both Georgia and Belarus are in line with nearly all parameters for an ideal MNP framework, identified by the best practice international research. In Belarus, the related technical approach and specific attributes have changed over time, from a donor-led, fee-based lengthy process in early years of MNP to a recipient-driven free-of-charge porting regime of reasonable duration that is available nowadays. So, from the technical standpoint these two deployments can be considered effective and compliant with internationally acceptable standards.

Telecommunications is currently one of the most dynamic and rapidly evolving economic sectors worldwide, bringing about continuous technological and service innovations. Hence, it should not come as a surprise that the MNP introduction coincided in time with other important sectoral developments by mobile operators such as the launch of $4 \mathrm{G}$ services, dramatic network coverage and service expansions, and widespread affordability of mobile communications, which all have had their unique as well as joint consequences on functioning of the market and behaviour of an end user.

One of the limitations of the present study is that it was hard to separate the effect of those developments from the impact of MNP, which would possibly require more complex econometric research. Nevertheless, the applied multistakeholder perspective approach had an advantage of analysing the broader picture and still allowing to make sense out of that combined effect on the telecoms field, where MNP played its concerted role.

Bearing in mind the above limitation, it is believed that the service availability alone has not had a considerable impact on individual market players and larger mobile communications segments in Georgia and Belarus. By itself, MNP has contributed to more active market competition and subscriber mobility, mostly benefitting the biggest service providers. It would thus be assumed that MNP has had a scattered and limited indirect effect on the market and its participants.

As such, this is the first comprehensive, ex post research on the impact of MNP in Georgia and Belarus, at least among those that are publicly available. Besides, it is a rare study in this domain, featuring a multi-stakeholder approach whereby the relevant primary data are collected from all involved parties, i.e., mobile operators, national regulatory/ policy-making authorities, and end users (analysis of the latter's survey being outside the scope of this publication).

The NRA/ policy-maker stakeholder category is often omitted from the discussion, as the formerly carried out MNP research predominantly focuses on either mobile operator-level panel data or end-user level survey data, or sometimes examines a combination of both. The given research counted in views and considerations of that important stakeholder group in addition to mobile operator and consumer perspectives. Such an approach was believed to ensure a more inclusive feedback on the MNP effects and it seems to have met this expectation. 
As earlier research shows, there were considerable variations in MNP patterns across countries. It is evident from highly heterogenous porting statistics from one country to another, and so the number of mobile portings cannot be regarded as a sole indicator for the success of MNP. Belarus and Georgia are not exceptions in this respect, with quite a low percentage of MNP users in the former country and the relatively large uptake of the service in the latter one.

Hence, in order to fully assess the impact of MNP, certain other factors apart from mere porting statistics should be taken into account, which occurred at around the same timing with the MNP launch and influenced the mobile telephony market. As such developments, introduction of the $3.5 \mathrm{G}$ service and market entry of a new mobile operator were referred to by Otsuka and Mitomo [14] in their research on the MNP implementation in Japan.

There are also explicit differences in findings between the given research and earlier studies on the effects of MNP, which are mainly attributable to the individual country and consumer specifics. According to Buehler at al. [9], MNP pursues the following two objectives: (1) it removes barriers to switch service providers and thus directly benefits mobile customers, and (2) it provides equitable conditions for new players to enter the market and generate a sufficient customer base to be able to compete with incumbents. While there is evidence that the first objective was achieved in the two studied countries, the second one remained largely unmet, which is concluded from the latest market entrants' direct feedback during interviews.

For the most part, the MNP availability in Georgia and Belarus benefitted the first two biggest players by further solidifying their market positions. It is also in contrast with findings of several other studies including by Cho at al. [10], whereby MNP normally reduces market concentration by taking it away from the incumbent operators.

In general, the multi-stakeholder approach applied herein attempted to achieve the following:

- A broader and inclusive outlook on the impact of MNP was indeed analysed through collecting and processing feedback from the major relevant parties all at once.

- The effect of the MNP policy objectives on the overall market performance was included by covering the voice of national regulatory and/or policy-making authorities - an important stakeholder group that had often been excluded from the former research.

- The attitudes toward MNP of all mobile operators in the country were considered, by thoroughly interviewing each of them to reveal their specific views with regard to the MNP implementation.

\section{References:}

1. Official Journal of the European Communities. Directive 2002/22/EC of the European Parliament and of the Council of 7 March 2002 on universal service and users' rights relating to electronic communications networks and services [Internet]. 2002 Apr [cited 2014 Mar 23]. Available from: http://eur-lex.europa.eu/legalcontent/EN/TXT/PDF/?uri=CELEX:32002L0022\&from=EN

2. Official Journal of the European Union. Directive 2009/136/EC of the European Parliament and of the Council of 25 November 2009 amending Directive 2002/22/EC on universal service and 
users' rights relating to electronic communications networks and services [Internet]. 2009 Dec [cited 2014 Mar 23]. Available from: http://eur-

lex.europa.eu/LexUriServ/LexUriServ.do?uri=OJ:L:2009:337:0011:0036:en:PDF

3. GSMA Intelligence. Majority of developing world mobile markets have no plans for MNP [Internet]. 2013 Nov [cited 2014 Jun 10]. Available from:

https://gsmaintelligence.com/files/analysis/?file=2013-11-22-majority-of-developing-worldmobile-markets-have-no-plans-for-mnp.pdf

4. International Telecommunication Union. List of indicators included in the World Telecommunication/ICT Indicators database [Internet]. 2016 Dec [cited 2017 Oct 2]. Available from: http://www.itu.int/en/ITU-

D/Statistics/Documents/statistics/2016/WTID_2016_ListOfIndicators.pdf

5. European Commission. Europe's Digital Progress Report 2017 country profiles - Telecom country reports [Internet]. 2017 May [cited 2017 Oct 2]. Available from: https://ec.europa.eu/digitalsingle-market/en/news/europes-digital-progress-report-2017-country-profiles-telecom-countryreports

6. Samarajiva R. Mobile Number Portability: Lessons from international experience [Internet] 2013 Jun [cited 2016 Feb 25]. Available from: http://lirneasia.net/wpcontent/uploads/2013/07/Samarajiva_June2012.pdf

7. Iqbal T. Mobile Number Portability in South Asia [Internet]. 2010 [cited 2016 Feb 25]. Available from: http://lirneasia.net/wp-content/uploads/2010/02/Mobile-2.0_MNP.pdf

8. Larkotey W, Ansong D, Damoah D, Abandoh-Sam J. Mobile Number Portability in Developing Countries: Its successes and failures. Case Study - West African Sub-Region. Int J of Societal Applications of Computer Science. 2012 Nov;1(1):44-54

9. Buehler S, Dewenter R, Haucap J. Mobile Number Portability in Europe. Telecommunications Policy. 2006 Aug;30(7):385-99

10. Cho D, Ferreira P, Telang R. The Impact of Mobile Number Portability on Price, Competition and Consumer Welfare [Internet]. 2013 May [cited 2015 Mar 6]. Available from: http://www.ibrarian.net/navon/paper/The_Impact_of_Mobile_Number_Portability_on_P rice_.pdf?paperid $=22214733$

11. Levin D. Mobile Number Portability - Impact Assessment. Synergy Consultant. 2006

12. European Bank for Reconstruction and Development. Electronic Communication Sector Comparative Assessment [Internet]. 2012 [cited 2014 Aug 27]. Available from: http://www.ebrd.com/downloads/legal/telecomms/comparative-assessment-2012.pdf

13. Telecommunications Management Group. Mobile Number Portability Around the World [Internet]. 2008 Oct [cited 2014 Dec 13]. Available from: http://tmgtelecom.com/portfolio/mobile-number-portability-around-the-world/

14. Otsuka T, Mitomo H. User benefits and operator costs of mobile number portability in Japan and impact on market competitiveness. Telecommunications Policy. 2013 May;37(4):345-56 


\section{Appendix A}

\section{Interview questionnaire for national regulatory authorities/ policy- making bodies}

1. What were the main objectives behind introducing the mobile number portability (MNP) service in your country?

2. Have you conducted any ex ante assessments/ feasibility studies on potential effects of MNP? If yes, what were the main targets/ market outcomes you were expecting MNP to achieve (e.g., in terms of the number of mobile portings, reduction in mobile prices, change in the market structure, etc.)?

3. Do you think your expectations have been met? Please justify your either positive or negative response by supporting it with qualitative and/or quantitative arguments.

4. In the course of implementing an MNP system, have you organised coordination meetings with all mobile operators to oversee and monitor the process? If yes, how often?

5. According to relevant research, an ideal MNP regime should have the following attributes:

- Porting process driven by the recipient network;

- Centralised, neutrally administered database;

- $\quad$ Direct call routing;

- Short porting times (normally one working day);

- Low or no porting fees for subscribers.

Does the MNP regime in your country satisfy all of the above characteristics? If not, please explain.

6. What was the model applied to database ownership, administration and management (e.g., by a consortium of mobile operators, by an independent entity, or by the national regulatory authority)? Do you think it was the right choice?

7. Do you think the MNP initial investment and subsequent maintenance cost have been reasonable, transparent and non-discriminatory for all involved mobile operators?

8. If mobile operators charge subscribers a fee for porting their numbers, do you think the price is reasonable and cost-oriented?

9. One of the aims of an efficient MNP regime is to limit cross-subsidisation between on-net and off-net tariffs. Do you think this has happened in your mobile market as a result of the MNP implementation? Please provide argumentation for your response. 
10. Do you think the MNP service availability has been sufficiently promoted by mobile operators through adequate marketing campaigns? If not, please explain.

11. Does your MNP regulation permit mobile subscribers to port their numbers during ongoing contract periods?

12. Are there any regulatory measures envisaged for mobile operators if they artificially delay the porting process (e.g., a requirement to compensate subscribers)?

13. Do you think the MNP implementation has had an overall positive impact on competition in the mobile telephony market of your country (e.g., in terms of taking market concentration away from the incumbent mobile operator, providing a level playing field for smaller operators to compete and enlarge their subscriber base, etc.)? Please justify your either positive or negative response by supporting it with qualitative and/or quantitative arguments. 


\section{Appendix B}

\section{Interview questionnaire for mobile operators}

1. What was your stance towards MNP before it was introduced? Were you opposing it, lobbying for it, or neutral?

2. What was the reason for your particular approach towards the MNP solution?

3. Have you conducted any ex ante assessments on potential effects of MNP on your company's performance? If yes, how has the latter been predicted to change as a result of the MNP service adoption (e.g., in terms of your market share, subscriber base, mobile revenues, etc.)?

4. What was the number of mobile portings you targeted to achieve within a specific timeframe, say, one year after the introduction of MNP?

5. Have your expectations been met? Have you carried out any ex post impact assessments to support your conclusions? If yes, please provide qualitative and/or quantitative findings from your analysis.

6. How do you evaluate the level of cooperation among mobile operators in the course of implementing an MNP system? Was it effective or not?

7. In your opinion, has the national regulatory authority provided sufficient oversight and expert advice during the process, e.g., through organising frequent coordination meetings with all mobile operators?

8. According to relevant research, an ideal MNP regime should have the following attributes:

- Porting process driven by the recipient network;

- Centralised, neutrally administered database;

- Direct call routing;

- Short porting times (normally one working day);

- Low or no porting fees for subscribers.

Does the MNP regime in your country satisfy all of the above characteristics? If not, please explain.

9. What was the model applied to database ownership, administration and management (e.g., by a consortium of mobile operators, by an independent entity, or by the national regulatory authority)? Do you think it was the right choice?

10. Do you think the MNP initial investment and subsequent maintenance cost have been reasonable, transparent and non-discriminatory for all involved mobile operators? Have you contributed an equal share of the total cost, or have your 
payments been proportionate with your company's size in terms of subscriber base or revenues?

11. Do you charge subscribers a fee for porting their numbers? If yes, do you think the price is reasonable and covers all your costs?

12. How have your mobile tariffs changed as a result of the MNP implementation? Please refer to changes in prices for both on-net and off-net calls.

13. Do you think the MNP service availability has been sufficiently promoted by your company through adequate marketing campaigns? Please provide argumentation for your either positive or negative response.

14. Do you conduct customer satisfaction surveys to reveal subscribers' perceptions of your company's mobile service quality? If yes, how often? If available, please share the results of your most recent survey.

15. Are your company subscribers allowed to port their mobile numbers during ongoing contract periods?

16. What kind of measures do you undertake to prevent subscriber churn? In particular, has your company initiated any loyalty programs, improved its mobile service quality, expanded its network coverage, and/or introduced additional services since the MNP launch?

17. Has your company ever been warned/ fined by the regulator for artificially delaying the porting process? If yes, please provide details.

18. Do you think the MNP implementation has had an overall positive impact on your company performance (e.g., in terms of enlarged subscriber base, increased mobile service revenues, etc.)? Please justify your either positive or negative response by supporting it with qualitative and/or quantitative arguments.

19. Do you think the mobile market in your country has eventually benefitted from the MNP service? Please provide argumentation for your either positive or negative response. 


\section{Appendix C}

\section{Stakeholders interviewed in Georgia}

1. Ministry of Economy and Sustainable Development of Georgia Address: 12 Chanturia Str., 0108 Tbilisi, Georgia

Fax: +995322935155

Website: www.economy.gov.ge

Mr. Jemal Vashakidze

Deputy Head of Communications, IT and Innovations Department

Tel: +995322991099

Cell: +995 595323333

E-mail: jvashakidze@economy.ge

Ms. Eka Kubusidze

Head of Info-communications Division

Communications, IT and Innovations Department

Tel: +995322991041

Cell: +995595220622

E-mail: ekubusidze@economy.ge

\section{Georgian National Communications Commission (GNCC)}

Address: 50/18 Bochorma Str., KetevanTsamebuli Ave., 0144 Tbilisi, Georgia

Website: www.gncc.ge

Ms. Irine Verdzeuli

Chief Specialist of Strategy Development Department

Tel: +99532231 1699

Cell: +995 599333050

E-mail: iverdzeuli@gncc.ge

\section{MagtiCom}

Address: 7 Politkovskaya Str., 0186 Tbilisi, Georgia

Website: www.magticom.ge

Mr. Nikoloz Davitashvili

Director of Institutional Market Department

Tel: +99532217 1431

Fax: +995 322171171

Cell: +995 595151313

E-mail: nikoloz.davitashvili@magticom.ge

\section{Mobitel Ltd (brand Beeline)}

Address: 8 Gorgasali Str., 0114 Tbilisi, Georgia

Website: www.beeline.ge

Mr. Irakli Esartia 
Head of Legal Department

Tel: +995322200606

Fax: +995 322200606

Cell: +995 597970014

E-mail: iesartia@beeline.ge

\section{Geocell LLC}

Address: 3 Gotua Str., 0160 Tbilisi, Georgia

Tel: +995322770100

Fax: +995 322770101

Website: www.geocell.ge

Mr. Levan Giorgadze

Director of "GL Consulting" LLC

Cell: +995 577188333

E-mail: giorgadzelevan.gl@gmail.com 


\section{Appendix D}

\section{Stakeholders interviewed in Belarus}

1. Ministry of Communications and Informatisation of the Republic of Belarus

Address: 10 Nezavisimosti Ave., 220050 Minsk, Belarus

Tel: +375 172878706

Fax: +375 173272157

Website: www.mpt.gov.by

Mr. Pavel Petrulevich

Head of Telecommunications Department

Tel: +375172878760

Fax: +37517222 2790

E-mail: ppa@mpt.gov.by

\section{BeST CJSC (brand life:) Belarus)}

Address: 24 Krasnoarmeyskaya Str., 220030 Minsk, Belarus

Tel: +375172959999

Fax: +37517328 5886

Website: www.life.com.by

Mr. Ismet Yazici

General Manager

Cell: +375 259090000

E-mail: ismet.yazici@life.com.by

\section{3. velcom}

Address: 36/2 Internatsionalnaya Ave., 220030 Minsk, Belarus

Tel: +375173303030

Fax: +375173303427

Website: www.velcom.by

Mr. Andrei Kulinkin

Regulatory Head

E-mail: a.kulinkin@velcom.by 